\title{
Компаративный анализ восприятия предпринимательских возможностей и способностей
}

\section{Юлия Пиньковецкая}

Ульяновский государственный университет, Ульяновск, Россия

\author{
Информация о статье \\ Поступила в редакиию: \\ 08.01 .2021 \\ Принята \\ к опубликованию: \\ 26.02.2021
}

УДК 332.05

JEL M20

\section{Ключевые слова:}

предпринимательство, восприятие возможностей, восприятие способностей, женщины, мужчины, гендерные различия

\footnotetext{
Keywords:

entrepreneurship, perception of opportunities, perception of abilities, women, men, gender differences
}

\begin{abstract}
Аннотация
Цель работь заключается в оченке уровня восприятия предпринимательских возможностей $u$ способностей взросльми людьми, созданными предпринимателями в современных национальных экономиках по данным за 2018 г. $B$ качестве исходной информации использовались результаты опросов, проведенных в 59 странах, в прочессе реализации проекта Глобального мониторинга предпринимательства. В исследовании рассматривалась оченка шести показателей, характеризующих мнение людей о наличии в их стране предпринимательских возможностей и способностей. Полученные результать доказали, что в большинстве стран имеет место гендерный разрыв между показателями восприятия предпринимательской активности.
\end{abstract}

\section{Comparative Analysis of the Perception of Entrepreneurial Opportunities and Abilities}

Iuliia Pinkovetskaia

\section{Abstract}

The article is devoted to the actual problem of the existing opinions of adults about the possibility and ability to participate in early entrepreneurial activity. The aim of the study is to assess the current levels of acceptance of these opportunities by women and men in modern national economies. The study solved the problem of determining the values of indicators that characterize the attitude of people to the creation of new own businesses. The study used the results of surveys conducted in 59 countries during the implementation of the Global Entrepreneurship Monitoring project as initial information. The study examined the assessment of six indicators that characterize the opinion of women and men about entrepreneurship, as well as the corresponding gender differences. Functions were obtained showing the distribution of indicators for 59 countries, describing the proportion of women and men who have the ability and ability to create their own businesses. In addition, gender differences were assessed. The results showed that in most countries there is a gender gap between indicators, that is, in these countries, women have fewer intentions to engage in entrepreneurship compared to men. The author's assessment of the values of indicators for Russia and foreign countries showed that both women and men in our country see less prospects for participation in entrepreneurship. The results obtained are new and original. They 
have theoretical and practical implications for Governments and entrepreneurs. The methodological approach to assessing gender differences in early entrepreneurship presented in the article can be used in further research. The new knowledge gained is of interest and can be used in the educational process at universities.

\section{Введение}

В настоящее время предприниматели играют значительную роль в экономиках большинства современных стран. Они являются владельцами абсолютного большинства фирм, как в развитых, так и развивающихся странах, создают около половины всех рабочих мест и обеспечивают конкуренцию на рынках товаров и услуг [1-3].

Одной из наиболее актуальных проблем развития современного предпринимательства является привлечение новых людей в создание бизнесов. Этот процесс во многом определяется воспринимаемыми предпринимательскими возможностями и способностями. Вопросы их восприятия взрослыми людьми рассматривалась в ряде научных публикаций. Так, воспринимаемые возможности нашли отражения в статьях [4-6]. Восприятие предпринимательских способностей рассматриваются в работах [7-9].

Учитывая возрастание роли гендерных исследований в предпринимательстве [10-13], наряду с межстрановым анализом в настоящей статье рассматриваются сложившиеся различия в восприятии предпринимательских возможностей и способностей женщин и мужчин.

Необходимо отметить, что в выполненных ранее научных исследованиях, проблеме гендерных различий, сложившихся в мнениях о предпринимательских возможностях и способностях, уделялось недостаточно внимания $[14,15]$.

Целью исследования является оценка уровня восприятия предпринимательских возможностей и способностей взрослыми людьми созданными предпринимателями, в современных национальных экономиках. Процесс исследования включал пять этапов. На первом этапе формировались исходные данные, описывающие мнения женщин и мужчин о наличии у них возможностей и способностей создания собственных бизнесов. На втором этапе оценивались значения показателей, характеризующих удельные значения женщин и мужчин, воспринимающих предпринимательские возможности и способности, в общей численности этих страт населения. На третьем этапе определялись средние значения указанных показателей по рассматриваемым странам и диапазоны, в которых находятся значения этих показателей для большинства из них. На четвертом этапе проводился компаративный анализ, в процессе которого устанавливались страны, в которых отмечались минимальные и максимальные значения показателей. На пятом этапе проводился сравнительный анализ значений показателей по России и зарубежным странам.

В качестве исходной информации в исследовании использовались результаты опросов, проведенных в 59 странах, в процессе реализации проекта Глобального мониторинга предпринимательства [16]. Опросы взрослого населения (18-64 лет) в этих странах позволили получить мнения людей о восприятии ими предпринимательских возможностей и способностей.

В нашем исследовании рассматривалась оценка шести показателей, характеризующих то, как женщины и мужчины оценивали свои возможности и способности создать новый бизнес по 59 странам в 2018 г/:

- удельный вес женщин, считающих, что у них есть возможности создания бизнеса, в численности взрослых женщин (показатель 1);

- удельный вес мужчин, считающих, что у них есть возможности создания бизнеса, в общей численности взрослых мужчин, (показатель 2); 
- отношение значений показателей, описывающих возможности создания бизнеса женщинами и мужчинами (показатель 3);

- удельный вес женщин, считающих, что у них есть способности создания бизнеса, в численности взрослых женщин (показатель 4);

- удельный вес мужчин, считающих, что у них есть способности создания бизнеса, в общей численности взрослых мужчин, (показатель 5);

- отношение значений показателей, описывающих способности создания бизнеса женщинами и мужчинами (показатель 10).

Проведенное исследование включало проверку пяти следующих гипотез:

- гипотеза 1 - в большинстве стран имеет место гендерный разрыв в уровнях воспринимаемых предпринимательских возможностей по женщинам и мужчинам;

- гипотеза 2 - в большинстве стран имеет место гендерный разрыв в уровнях воспринимаемых предпринимательских способностей по женщинам и мужчинам;

- гипотеза 3 - значения рассматриваемых шести показателей имеют существенную дифференциацию по разным странам;

- гипотеза 4 - территориальное расположение стран не оказывает существенного влияния на значения каждого из шести показателей;

- гипотеза 5 - уровень доходов населения в рассматриваемых странах не оказывает существенного влияния на значения каждого из шести показателей.

\section{Результаты вычислительного эксперимента}

В экономико-математическом моделировании, используемом для оценки каждого из шести показателей, применялись функции нормального распределения. В статье автора [17] представлен методический подход к их разработке и использованию для определения средних значений по рассматриваемым государствам, а также диапазонов вариации значений по большинству государств. В процессе нашей работы устанавливались государства с максимальными и минимальными величинами показателей.

В процессе вычислительного эксперимента проводилось экономико-математическое моделирование на основе эмпирических данных. Модели, которые описывают распределения шести показателей по всем 59 странам, продемонстрированы далее:

- удельный вес женщин, считающих, что у них есть возможности создания бизнеса, в численности взрослых женщин, \%

$$
y_{1}\left(x_{1}\right)=\frac{700,63}{16,05 \times \sqrt{2 \pi}} \cdot e^{-\frac{\left(x_{1}-42,86\right)^{2}}{2 \times 16,05 \times 16,05}}
$$

- удельный вес мужчин, считающих, что у них есть возможности создания бизнеса, в общей численности взрослых мужчин, \%

$$
y_{2}\left(x_{2}\right)=\frac{560,52}{16,07 \times \sqrt{2 \pi}} \cdot e^{-\frac{\left(x_{2}-47,45\right)^{2}}{2 \times 16,07 \times 16,07}} ;
$$

- отношение значений показателей, описывающих возможности создания бизнеса женщинами и мужчинами

$$
y_{3}\left(x_{3}\right)=\frac{5,16}{0,10 \times \sqrt{2 \pi}} \cdot e^{-\frac{\left(x_{3}-0,89\right)^{2}}{2 \times 0,10 \times 0,10}} .
$$

- удельный вес женщин, считающих, что у них есть способности создания бизнеса, в численности взрослых женщин, \% 


$$
y_{4}\left(x_{4}\right)=\frac{674,29}{14,02 \times \sqrt{2 \pi}} \cdot e^{-\frac{\left(x_{4}-43,91\right)^{2}}{2 \times 14,02 \times 14,02}}
$$

- удельный вес мужчин, считающих, что у них есть способности создания бизнеса, в общей численности взрослых мужчин, \%

$$
y_{5}\left(x_{5}\right)=\frac{590,12}{13,10 \times \sqrt{2 \pi}} \cdot e^{\frac{-\left(x_{5}-55,28\right)^{2}}{2 \times 13,10 \times 13,10}}
$$

- отношение значений показателей, описывающих способности создания бизнеса женщинами и мужчинами

$$
y_{6}\left(x_{6}\right)=\frac{6,64}{0,13 \times \sqrt{2 \pi}} \cdot e^{-\frac{\left(x_{6}-0,77\right)^{2}}{2 \times 0,13 \times 0,13}} .
$$

Высокое качество функций (1)-(6) было подтверждено в процессе тестирования по критериям Шапиро-Вилка, Пирсона и Колмогорова-Смирнова.

На следующем этапе исследования были выявлены закономерности, характеризующие сложившуюся занятость в фирмах предпринимателей-женщин и предпринимателей-мужчин, а также ее предполагаемый рост по рассматриваемым экономикам. В столбце 2 (таблица 1) приведены данные, характеризующие средние величины показателей. Диапазоны, в которых находятся значения показателей по большинству стран, продемонстрированы в третьем столбце таблицы.

Таблица 1

Значения показателей, характеризующих воспринимаемые предпринимательские возможности и способности

\begin{tabular}{|l|c|c|}
\hline \multicolumn{1}{|c|}{ Наименование показателя } & $\begin{array}{c}\text { Средние ве- } \\
\text { личины }\end{array}$ & $\begin{array}{c}\text { Значения по боль- } \\
\text { шинству стран }\end{array}$ \\
\hline $\begin{array}{l}\text { удельный вес женщин, считающих, что у них есть } \\
\text { возможности создания бизнеса, в численности взрос- } \\
\text { лых женщин \% }\end{array}$ & 42,86 & $26,81-58,91$ \\
\hline $\begin{array}{l}\text { удельный вес мужчин, считающих, что у них есть } \\
\text { возможности создания бизнеса, в общей численности } \\
\text { взрослых мужчин, \% }\end{array}$ & 47,45 & $31,38-63,52$ \\
\hline $\begin{array}{l}\text { отношение значений показателей, описывающих воз- } \\
\text { можности создания бизнеса женщинами и мужчи- } \\
\text { нами }\end{array}$ & 0,89 & $0,79-0,99$ \\
\hline $\begin{array}{l}\text { удельный вес женщин, считающих, что у них есть } \\
\text { способности создания бизнеса, в численности взрос- } \\
\text { лых женщин, \% }\end{array}$ & 43,91 & $29,89-57,91$ \\
\hline $\begin{array}{l}\text { удельный вес мужчин, считающих, что у них есть } \\
\text { способности создания бизнеса, в общей численности } \\
\text { взрослых мужчин, \% }\end{array}$ & 55,28 & $42,18-18,38$ \\
\hline $\begin{array}{l}\text { отношение значений показателей, описывающих спо- } \\
\text { собности создания бизнеса женщинами и мужчинами }\end{array}$ & 0,77 & $0,64-0,90$ \\
\hline
\end{tabular}

Источник: составлено автором на основе [1-6]

\section{Обсуждение результатов}

Среднее значение удельного веса женщин, считающих, что у них есть возможности создания бизнеса, в численности взрослых женщин, достигало в 2018 г. почти 42,9\%. Соответствующий показатель по мужчинам был (в 1,1 раза) больше $-47,45 \%$. Тенденция превышения указанного показателя по мужчинам характерна для большинства стран. Исключения наблюдались в ряде стран. В трех странах, а именно в Аргентине, Индонезии, и Вьетнаме значения показателей по женщинам и мужчинам были равны. В пяти странах, а именно Латвии, 
Казахстане, ОАЭ, Тайване и Российской Федерации воспринимаемые возможности создания женских бизнесов были выше, чем мужских. Среднее значение отношения величин показателей, описывающих предпринимательские возможности женщин и мужчин, составило в 2018 г. 0,89. Таким образом, гипотеза 1 о наличии в большинстве стран гендерного разрыва в уровнях воспринимаемых возможностей по женщинам и мужчинам, подтвердилась.

Данные таблицы 1 свидетельствуют, что в рассматриваемых странах относительное меньшинство населения воспринимает возможность предпринимательской деятельности, как начало, либо продолжение своей жизненной карьеры.

Среднее значение удельного веса женщин, считающих, что у них есть способности для создания бизнеса, в численности взрослых женщин, достигало в 2018 г. почти 43,9\%. Соответствующий показатель по мужчинам был в 1,2 раза больше $-55,3 \%$. Тенденция превышения указанного показателя по мужчинам характерна для большинства стран. Исключения наблюдались в ряде стран. В шести странах, а именно в Индонезии, Кипре, Израиле, Казахстане, Саудовской Аравии и Вьетнаме значения показателей по женщинам и мужчинам были равны. В Анголе воспринимаемые способности создания женских бизнесов были выше, чем мужских. Среднее значение отношения величин показателей, описывающих предпринимательские возможности женщин и мужчин, составило в 2018 году 0,77. Таким образом, гипотеза 2 о наличии в большинстве стран гендерного разрыва в уровнях воспринимаемых способностей по женщинам и мужчинам, подтвердилась.

Необходимо отметить, что, по мнению, как женщин, так и мужчин уровень их предпринимательских способностей несколько выше уровня предпринимательских возможностей.

Для проверки гипотезы 3 проводился анализ данных, представленных в столбце 3 табл. 1. Анализ показал существенную дифференциацию по рассматриваемым странам значений каждого из шести показателей. Следовательно, третья гипотеза подтвердилась.

На следующем этапе выявлялись страны, в которых отмечались максимальные и минимальные значения каждого из показателей. При этом, к максимальным и минимальным относятся значения, соответственно превышающие верхние границы диапазонов, продемонстрированных в столбце 3 табл. 1 и меньшие нижних границ диапазонов. Итоги этого анализа приведены в табл. 2. Наряду с перечнями стран в этой таблице представлено также подразделение выявленных стран по их географическому положению и уровню доходов населения.

Таблииа 2

Страны с максимальными и минимальными значениями показателей

\begin{tabular}{|c|c|c|}
\hline $\begin{array}{c}\text { Наименование } \\
\text { показателя }\end{array}$ & Максимальные значения & Минимальные значения \\
\hline $\begin{array}{l}\text { Удельный вес } \\
\text { женщин, считаю- } \\
\text { щих, что у них } \\
\text { есть возможности } \\
\text { создания бизнеса, } \\
\text { в численности } \\
\text { взрослых женщин } \\
\%\end{array}$ & $\begin{array}{l}\text { Канада, Эстония, ОАЭ, Нидер- } \\
\text { ланды, США, Польша, Судан, Ан- } \\
\text { гола, Саудовская Аравия, Шве- } \\
\text { ция. Расположены в Европе че- } \\
\text { тыре страны, в Северной Аме- } \\
\text { рике, Азии и Африке по две } \\
\text { страны. Доходы населения: высо- } \\
\text { кие (восемь стран), низкие (две } \\
\text { страны). }\end{array}$ & $\begin{array}{l}\text { Япония, Босния и Герцеговина, Греция, } \\
\text { Болгария, Иран, Российская Федерация, } \\
\text { Франция, Испания. Шесть стран распо- } \\
\text { ложены в Европе, в Азии - две страны. } \\
\text { Высокие доходы населения отмечаются } \\
\text { в четырех странах, средние в трех стра- } \\
\text { нах, а низкие в одной стране. }\end{array}$ \\
\hline
\end{tabular}




\begin{tabular}{|c|c|c|}
\hline $\begin{array}{l}\text { Удельный вес } \\
\text { мужчин, считаю- } \\
\text { щих, что у них } \\
\text { есть возможности } \\
\text { создания бизнеса, } \\
\text { в общей числен- } \\
\text { ности взрослых } \\
\text { мужчин, \% }\end{array}$ & $\begin{array}{l}\text { Чили, ОАЭ, Канада, Польша, Ни- } \\
\text { дерланды, Судан, США, Ангола, } \\
\text { Саудовская Аравия, Швеция. Рас- } \\
\text { положены в Европе три страны, в } \\
\text { Азии, Африке и Северной Аме- } \\
\text { рике по две страны, в Латинской } \\
\text { Америке одна страна. Доходы } \\
\text { населения высокие (восемь } \\
\text { стран), низкие (две страны). } \\
\end{array}$ & $\begin{array}{l}\text { Япония, Босния и Герцеговина, Болга- } \\
\text { рия, Греция, Российская Федерация, } \\
\text { Иран, Тайвань, Уругвай, Испания. Пять } \\
\text { стран расположены в Европе, три } \\
\text { страны - в Азии, одна страна в Латин- } \\
\text { ской Америке. Доходы населения: вы- } \\
\text { сокие (четыре страны), средние (четыре } \\
\text { страны), низкие (одна страна). }\end{array}$ \\
\hline $\begin{array}{l}\text { ге значе-. } \\
\text { ателей, } \\
\text { щих } \\
\text { сти со- } \\
\text { знеса } \\
\text { пи и } \\
\text { пи }\end{array}$ & $\begin{array}{l}\text { Аргентине, Индонезии, Вьетнаме, } \\
\text { Латвии, Казахстане, ОАЭ, Тай- } \\
\text { ване, Российской Федерации. Две } \\
\text { страны расположены в Европе, } \\
\text { одна страна в Латинской Аме- } \\
\text { рике, в Азии - пять стран. Доходы } \\
\text { населения: высокие (две страны), } \\
\text { средние (три страны), низкие (две } \\
\text { страны). }\end{array}$ & $\begin{array}{l}\text { я, Босния и Герцеговина, Еги- } \\
\text { ония, Словацкая Республика, } \\
\text { Германия, Индия. Четыре из } \\
\text { оан расположены в Европе, три } \\
\text { в Азии, одна страна в Африке. } \\
\text { е доходы населения имели ме- } \\
\text { тырех странах, средние и низкие } \\
\text { были в двух странах соответ- } \\
\text {. }\end{array}$ \\
\hline $\begin{array}{l}\text { ес жен- } \\
\text { ющих, } \\
\text { сть } \\
\text { и со- } \\
\text { неса, в } \\
\text { кенщин, }\end{array}$ & $\begin{array}{l}\text { па, Колумбия, Судан, } \\
\text { захстан, Индонезия, Ан- } \\
\text { вадор, Саудовская Ара- } \\
\text { положены в Азии три } \\
\text { в Латинской Америке че- } \\
\text { аны, в Африке - две } \\
\text { Доходы населения: высо- } \\
\text { а страна), средние (пять } \\
\text { изкие (три страны). }\end{array}$ & $\begin{array}{l}\text { Япония, Китай, Российская Федерация, } \\
\text { Тайвань, Италия, Марокко, Швейцария, } \\
\text { Босния и Герцеговина, Швеция, Фран- } \\
\text { ция. Пять из этих стран расположены в } \\
\text { Европе, три страны в Азии, одна страна } \\
\text { в Африке. Высокие доходы населения } \\
\text { отмечаются в шести странах, средние в } \\
\text { двух странах, низкие доходы в одной } \\
\text { стране. }\end{array}$ \\
\hline $\begin{array}{l}\text { удельный вес } \\
\text { мужчин, считаю- } \\
\text { щих, что у них } \\
\text { есть способности } \\
\text { создания бизнеса, } \\
\text { в общей числен- } \\
\text { ности взрослых } \\
\text { мужчин, \% }\end{array}$ & $\begin{array}{l}\text { Гватемала, Колумбия, Ан- } \\
\text { Перу, Эквадор, Ливан, Су- } \\
\text { 'аудовская Аравия. По две } \\
\text { ы расположены в Азии и } \\
\text { ке, в Латинской Америке - } \\
\text { тран. Доходы населения вы- } \\
\text { (две страны), средние (че- } \\
\text { страны), низкие (три } \\
\text { ы). }\end{array}$ & $\begin{array}{l}\text { Япония, Китай, Российская Федерация, } \\
\text { Тайвань, Марокко, Италия, Израиль. } \\
\text { Две страны расположены в Европе, } \\
\text { одна страна - в Африке, четыре страны } \\
\text { - в Азии. Доходы населения: высокие } \\
\text { (четыре страны), средние (две страны), } \\
\text { низкие (одна страна). }\end{array}$ \\
\hline $\begin{array}{l}\text { Отношение значе } \\
\text { ний показателей, } \\
\text { описывающих } \\
\text { способности со- } \\
\text { здания бизнеса } \\
\text { женщинами и } \\
\text { мужчинами }\end{array}$ & $\begin{array}{l}\text { Кипр } \\
\text { стан, } \\
\text { нам, } \\
\text { расп } \\
\text { в АзІ } \\
\text { лени } \\
\text { сред } \\
\text { три }\end{array}$ & $\begin{array}{l}\text { Япония, Босния и Герцеговина, Фран- } \\
\text { ция, Иран, Италия, Люксембург, Нидер- } \\
\text { ланды, Швеция, Швейцария. Семь из } \\
\text { этих стран расположены в Европе, две } \\
\text { страны в Азии. Высокие доходы населе- } \\
\text { ния имели место в восьми странах, а в } \\
\text { одной стране - низкие доходы. }\end{array}$ \\
\hline
\end{tabular}

Источник: разработано автором на основе данных таблицы 1 и проекта Глобального мониторинга предпринимательства

В табл. 2 приведена информация по территориальному расположению стран с высокими (столбец 2) и низкими (столбец 3) значениями каждого из девяти оцениваемых в нашем исследовании показателей. Анализ этой информации показал, что связи между значениями показателей и территориальным расположением стран, а также уровнем доходов населения в этих странах, не наблюдается. То есть, страны с высокими и низкими значениями показателей, расположены в различных частях света и характеризуются разным уровнем доходов населения. Таким образом, можно констатировать подтверждение гипотез 4 и 5.

Сравнительный анализ значений рассматриваемых показателей по России и зарубежным странам позволил сделать следующие выводы:

- значение показателя 1 составляет 23,3\%, что в 1,8 раз меньше средней величины по зарубежным странам; 
- значение показателя 2 составляет 22,3\%, что в 2,1 раз меньше средней величины по зарубежным странам;

- значение показателя 3 составляет 1,04, что в 1,2 раза выше средней величины по зарубежным странам;

- значение показателя 4 составляет $22,2 \%$, что в 2 раза выше средней величины по зарубежным странам;

- значение показателя 5 составляет $33,1 \%$, что в 1,7 раза меньше средней величины по зарубежным странам;

- значение показателя 6 составляет 0,67 , что в 1,1 раза меньше средней величины по зарубежным странам.

Таким образом, воспринимаемые предпринимательские возможности и способности взрослого населения в России существенно ниже по сравнению с зарубежными странами.

\section{Заключение}

Цель исследования, заключавшаяся в оценке мнений людей об имеющихся предпринимательских возможностях и способностях в национальных экономиках по данным за 2018 г., была достигнута. К выводам, обладающим научной новизной и оригинальностью, относятся:

1. Проведена оценка показателей, описывающих восприятие женщинами и мужчинами возможностей и способностей создания бизнесов.

2. Проведено моделирование распределения шести показателей, описывающих гендерные различия по 59 странам.

3. Доказано, что в большинстве стран удельные веса женщин, имеющих предпринимательские возможности и способности, ниже по сравнению с аналогичными показателями по мужчинам.

4. В 2018 году имели место существенные различия в значениях шести рассматриваемых показателей по странам.

8. Выявлены страны, для которых были характерны максимальные и минимальные значения этих шести показателей.

9. Проведено сопоставление значений показателей по России и зарубежным странам.

Итоги проведенной нами работы обладают определенным теоретическим и практическим значением для правительств и предпринимателей. Представленный в статье методический подход к оценке гендерных различий восприятии предпринимательства может применяться в дальнейших исследованиях. Полученные новые знания представляют интерес и могут использоваться в образовательном процессе в университетах.

В процессе исследования присутствовали ограничения на эмпирические данные, обусловленные тем, что рассматривалась информация только по 59 странам.

\section{Список источников / References}

1. Kraemer-Eis H., Lang F., Torfs W., Gvetadze S. European Small Business Finance Outlook. June 2017. EIF Working Paper 2017/43. 2017. [Электронный ресурс]. URL: http://www.eif.org/news_centre/research/index.htm (дата обращения: 16.12.2020).

2. Borbás L. The Role of SMEs in the European Entrepreneurship Policy // Volume of Management, Enterprise and Benchmarking in the 21st Century II. Óbuda University, Keleti Faculty of Business and Management, 2015, p. 71-88.

3. Muller P., Julius J., Herr D., Koch L., Peycheva V., Mckiernan S. Annual Report on European SMEs 2016/2017. SME Performance Review. European Union. DirectorateGeneral for Internal Market, Industry, Entrepreneurship and SMEs. 2017. 
[Электронный ресурc]. URL: https://www.researchgate.net/publication/321268021 (дата обращения: 20.12.2020).

4. Renko M., Shrader R., Simon M. Perception of Entrepreneurial Opportunity: A General Framework // Management Decision, 2012, Vol. 50 (7), p. 1233-1251.

5. Davidsson P. Entrepreneurial opportunities and the entrepreneurship nexus: A reconceptualization // Journal of Business Venturing, 2015, Vol. 30 (5), p. 674-695.

6. Liñán F., Santos F., Fernández J. The influence of perceptions on potential entrepreneurs // International Entrepreneurship and Management Journal, 2011, Vol. 7, p. 373390.

7. Bayon M., Vaillant Y., Lafuente E. Antecedents of perceived entrepreneurial ability in Catalonia: the individual and the entrepreneurial context // Journal of Global Entrepreneurship Research, 2012, Vol. 5 (3), DOI: 10.1186/s40497-015-0020-0.

8. Walker J. K., Jeger M., Kopecki D. The role of perceived abilities, subjective norm, and intentions // Journal of Entrepreneurship, 2013, Vol. 22 (2), p. 181-202.

9. Naser M., Afzal I., Siddiqui S., Dutta S. Determinants of entrepreneurial capability (EC) environment in ASEAN-05 economies - a log-linear stochastic frontier analysis // Journal of Global Entrepreneurship Research, 2018, Vol. 8 (14), DOI: 10.1186/s40497-0180101-y.

10. Carlianne P., Stephens H., Weinstein A. Where are all the self-employed women? Push and pull factors influencing female labor market decisions // Small Business Economics, 2016, Vol. 46 (3), p. 365-390. DOI: 10.1007/s11187-015-9697-2.

11. Chhabra M., Karmarkar Y. Gender gap in entrepreneurship - a study of small and micro enterprises // ZENITH International Journal of Multidisciplinary Research, 2016, Vol. 6 (8), p. 82-99.

12. Sperber S., Linder C. Gender-specifics in startup strategies and the role of the entrepreneurial ecosystem // Small Business Economics, 2018, Vol. 53(4), p. 1-14, DOI: 10.1007/s11187-018-9999-2.

13. Grosser K., Moon J. CSR and feminist organization studies: towards an integrated theorization for the analysis of gender issues // Journal of Business Ethics, 2019, Vol. 155 (2), p. 321-342, DOI: 10.1007/s10551-017-3510-x.

14. Dabic M., Daim T., Bayraktaroglu E., Novak I., Basic M. Exploring gender differences in attitudes of university students towards entrepreneurship // International Journal of Gender and Entrepreneurship, 2012, Vol. 4 (3), p. 316-336.

15. Tsai K.H., Chang H.C., Peng C.Y. Refining the linkage between perceived capability and entrepreneurial intention: roles of perceived opportunity, fear of failure, and gender // International Entrepreneurship Management Journal, 2016, Vol. 12, p. 1127-1145.

16. Global Entrepreneurship Monitor 2018/2019. Women's Entrepreneurship Report. Global Entrepreneurship Research Association (GERA). London Business School, London, United Kingdom. 2019.

17. Pinkovetskaia I., Slepova V. Estimation of Fixed Capital Investment in SMEs: the Existing Differentiation in the Russian Federation // Business Systems Research, 2018, Vol. 9 (1), p. 65-78, DOI: 10.2478/bsrj-2018-0006.

\section{Сведения об авторе / About author}

Пиньковецкая Юлия Семеновна, кандидат экономических наук, доцент кафедры экономического анализа и государственного управления, Ульяновский государственный университет. 432000 Россия, г. Ульяновск, ул. Л. Толстого, 42. E-mail: judy54@yandex.ru

Iuliia S. Pinkovetskaia, Candidate of Economics Sciences, Associate Professor at the Department of Economy Analysis and State Management, Ulyanovsk State University. 42, L. Tolstogo str., Ulyanovsk, Russia 432000.E-mail: judy54@yandex.ru 